Résumés des conférences et travaux

\title{
Philologie et épigraphie hébraïques et araméenne
}

\section{André Lemaire}

\section{OpenEdition \\ Journals}

\section{Édition électronique}

URL : https://journals.openedition.org/ashp/1261

DOI : 10.4000/ashp.1261

ISSN : 1969-6310

\section{Éditeur}

Publications de l'École Pratique des Hautes Études

\section{Édition imprimée}

Date de publication : 1 octobre 2012

Pagination : 21-22

ISSN : 0766-0677

\section{Référence électronique}

André Lemaire, "Philologie et épigraphie hébraïques et araméenne », Annuaire de l'École pratique des hautes études (EPHE), Section des sciences historiques et philologiques [En ligne], 143|2012, mis en ligne le 20 septembre 2012, consulté le 03 août 2021. URL : http://journals.openedition.org/ashp/1261 DOI : https://doi.org/10.4000/ashp.1261 


\title{
PHILOLOGIE ET ÉPIGRAPHIE HÉBR AÏQUES ET ARAMÉENNES
}

\author{
Directeur d'études : M. André Lemaire, \\ correspondant de l'Institut
}

Programme de l'année 2010-2011 : Épigraphie ouest-sémitique : méthodologie et inscriptions inédites ou méconnues du Ier millénaire av. J.-C. au IIIe s. apr. J.-C.

Après un rapide rappel du domaine de l'épigraphie ouest-sémitique, de sa méthodologie et de ses principaux outils de travail, nous avons étudié plusieurs stèles funéraires phéniciennes d'une collection privée libanaise, provenant apparemment du cimetière de Tyr el-Bass situé face à l'île antique. Ces stèles souvent inscrites avec le nom du défunt et datant du Fer II ( $\mathrm{IX}^{\mathrm{e}}-$ début du VI ${ }^{\mathrm{e}} \mathrm{s}$. av. J.-C.) constituent les plus anciennes inscriptions de cette capitale phénicienne et révèlent, à travers l'onomastique, quelque chose de son culte et de sa religion à cette époque. Nous avons étudié quelques stèles avec des noms tels que ŠQY, ŚM'Z, MQNB'L, 'BDL'Y, MLQRTKL, YMY BN 'MT'ŠMN, 'ŠTRTSMK... Deux stèles comportent une formule un peu plus développée : MṢBT 'ŠT' BN 'Z, « stèle de 'Ashtâ fils de 'Az » et MTR KHN 'ŠTRT 'SY, « Matar prêtre de 'Ashtart-Isis ». Toute cette collection sera publiée avec le Dr. Gaby Abousamra dans un volume actuellement sous presse.

Nous avons ensuite étudié un certain nombre d'ostraca paléo-hébreux de la collection Moussaieff, publiés par M. Heide dans différents articles, en utilisant de nouvelles photographies. Cette révision nous a permis de proposer une nouvelle interprétation de l'ostracon mentionnant du blé et du vin (M. Heide, "Wheat and Wine. A New Ostracon from the Shlomo Moussaieff Collection », Biblische Notizen, 114-115 [2002], p. 40-46) : il s'agit probablement d'un exercice de comptabilité. Un autre ostracon ("Impression from a New Alphabetic Ostracon... », dans M. Lubetski [éd.], New Seals and Inscriptions, Hebrew, Idumean and Cuneiform, Sheffield, 2007, p. 148-152) est aussi visiblement un exercice d'apprentissage de l'écriture. Un troisième ostracon nous a permis de corriger l'interprétation d'un chiffre hiératique. Deux ostraca sont des listes de nom propres. Le premier (ibidem, p. 170-174) est apparemment daté de « la deuxième année » en tenant compte d'une faute probable d'orthographe par lettre non redoublée et pourrait représenter une listes de militaires présentés par groupes de quatre ; le second est un grand ostracon, d'un format proche de A4, comportant une liste de noms propres de 27 lignes (« Ein 27-zeiliges Listenostrakon aus der Sammlung Shlomo Moussaieff », Ugarit-Forschungen, 39 [2007], p. 399412). Nous avons proposé quelques corrections de lecture pour certains de ces noms propres. Un autre ostracon semble assez énigmatique ( « One Sack for a Beqa“ of Jerusalem », dans R. Deutsch [éd.], Shlomo. Studies in Epigraphy, Iconography, History and Archaeology in Honor of Shlomo Moussaieff, Tel Aviv - Jaffa, 2003, p. 105-131). L'editio princeps a, apparemment à juste titre, interprété les cinq premières lignes 
comme une liste de champs avec l'indication de leur production de grains mesurée en kors mais, à la différence de l'editio princeps, il nous semble que cette interprétation s'impose aussi pour les lignes suivantes, en particulier pour les lignes 6, 8-9, 11 et 13, même si on y lit « Jérusalem » et peut-être " Idnah ». Une telle liste de champs avec leur production pourrait faire partie des documents préparatoires à l'établissement d'un cadastre pour la levée des impôts. L'étude des ostraca de cette collection se poursuivra l'année prochaine. 